the same as that for $\mathrm{H}$. The excitation temperature is defined by the relation:

$$
\frac{n_{i}}{n_{0}}=\frac{g_{i}}{g_{0}} e^{(-h v) /\left(k T_{s}\right)}
$$

where $n_{i}$ and $n_{0}$ are the densities of radicals in the upper and lower states of the transition, respectively. For $\mathrm{H}$ it has been shown that $T_{s}$ equals the kinetic temperature in a typical galactic gas cloud ${ }^{10}$ because radiative transitions are relatively rare as compared with collisional transitions. For $\mathrm{OH}$, however, the spontaneous transition probability is $10^{4}$ times larger than for $H$, so radiative transitions play a more dominant part in establishing the equilibrium population distribution. A detailed evaluation of the processes that will be important in determining the $\mathrm{OH}$ excitation temperature has not been made, but $\mathrm{a}_{\mathrm{o}}$ preliminary investigation shows that slow-moving positive ions may be very effective in inducing transitions between the two states, in spite of their low abundance in a $\mathrm{H}$ cloud $^{11}$. This situation arises because the $\mathrm{OH}$ transition is of an electric dipole type, and therefore can be induced by the Coulomb field of electrons and ions which leads to large interaction radii. A similar result has been obtained by Purcell when considering the population of the finestructure states of the $n=2$ level of $H$ in the solas atmosphere $^{12}$. An upper limit on $T_{s}$ can be set by our observations off Cassiopeia $A$ from which one would expect to detect $\mathrm{OH}$ emission. From the preliminary observations we conclude that any $\mathrm{OH}$ emission adjacent to Cassiopeia $A$ is less than $1^{\circ} \mathrm{K}$; this result implies a $T_{s}$ less than $50^{\circ} \mathrm{K}$ for an optical depth of 0.02 . For purposes of computing the total number of $\mathrm{OH}$ radicals from the foregoing equations we have assumed a $T_{s}$ of $10^{\circ} \mathrm{K}$. More extensive observations for $\mathrm{OH}$ emission will enable a better estimate of this quantity to be made.

The values of the number of $\mathrm{OH}$ radicals per $\mathrm{cm}^{2}$ in the direction of Cassiopeia $A$ are shown in Table 1. The $\mathrm{OH} / \mathrm{H}$ abundance ratio can be calculated from the results of the $\mathrm{H}$ absorption on Cassiopeia $A^{7}$, and gives typical ratios of $1 \times 10^{-7}$ (see Table 1). This ratio can be compared with estimates of the $\mathrm{CH} / \mathrm{H}$ abundance ratio $10^{-6}$ by Stromgren ${ }^{13}$ and $2 \times 10^{-8}$ by Bates and Spitzer ${ }^{14}$.
Our observations have enabled a more accurate determination of the firequencies of the two strongest $\Lambda$-type doublet lines of OH. The laboratory and astronomical values are shown in Table 2 . It is possible that these values will be of interest to the molecular spectroscopist for a more accurate evaluation of the hyperfine coupling constants.

\begin{tabular}{|c|c|c|}
\hline Transition & $\begin{array}{l}\text { Laboratory } \\
\text { measurement }\end{array}$ & $\begin{array}{c}\text { Astronomical } \\
\text { measurement }\end{array}$ \\
\hline $\begin{array}{l}F=2 \rightarrow 2 \\
F=1 \rightarrow 1\end{array}$ & $\begin{array}{l}1,667,340 \pm 30 \mathrm{kc} / \mathrm{s} \\
1,665,460 \pm 100 \mathrm{kc} / \mathrm{s}\end{array}$ & $\begin{array}{l}1,667,357.7 \mathrm{kc} / \mathrm{s} \\
1,665,402 \pm 7 \mathrm{kc} / \mathrm{s}\end{array}$ \\
\hline
\end{tabular}

We thank many people for their co-opcration in this experiment. We also thank R. E. Gay, P. J. Conrad, C. Blake, R. H. Erickson, J. F. MacLeod, and the entire personnel of the Millstone Hill Observatory for their assistance.

The work of one of us (A. H. B.) was supported in part by the U.S. Army, the Air Force Office of Scientific Research, and the Office of Naval Resoarch, and in part by the National Aeronautics and Space Administration (Grant $N s G-419$ ). Lincoln Laboratory is a centre for research and development operated by Massachusetts Institute of Technology with the support of the U.S. Air Force.

1 Ehrenstein, G., Townes, C. H., and Stevenson, M. J., Phys. Rev. Letters, 3, $40(1959)$.

"Shklovsky, I. S., Dok. Akad. Nauk. (SSSR), 92, 25 (1953).

${ }^{3}$ Townes, C. H., Intern. Astro. Union Symp., No. 4, edit. by van de Hulst, II. C., 92 (Cambridge Univ. Press, 1957).

4 Barrett, A. H., and Lilley, A. E., Astro. J., 62, 5 (1957).

"Penzias, A. A., Abst. Paper New England Radio Eng. and Manufacturers (Nov, 4-6, 1963).

${ }^{6}$ Weinreb, S., Tech. Rep. 412, Res. Lab. Electronics, M.I.T., Cambridge, Mass. (Aug. 30, 1963).

${ }^{7}$ Muller, C. A., Symp. Radio Astronomy, Paris, edit. by Bracewell, R. N. 360 (Stanford Univ. Press, Stanford, Calif., 1959).

${ }^{8}$ Dousmanis, G. C., Saunders, jun., T. M., and Townes, C. H., Phys. Rev., $100,1735(1955)$

${ }^{9}$ Ehrenstein, G., Ph.D. thesis, Columbia Univ., New York (1960).

${ }^{20}$ Purcell, E. M., and Field, G. B., Astrophys. J., 124, 542 (1955).

11 Barrett, A. Hr., and Lilley, A. E., Astro. J., 62, 4 (1957).

12 Purcell, E. M., Astrophys. J., 116, 457 (1952).

${ }^{13}$ Stromgren, B., Astrophys. J., 108, 242 (1948).

${ }^{14}$ Bates, D. R., and Spitzer, jun., L., Astrophys. J., 113, 441 (1951).

\title{
OBITUARIES
}

\section{Dr. A. A. Griffith, C.B.E., F.R.S.}

Althovgr the name of Dr. A. A. Griffith, who died on October 11, was not well known by the general public, he was a creative and original thinker who had considerable influence on the development of jet propulsion systems. A champion of the high-efficiency axial compressor while Whittle was experimenting with the more robust centrifugal engines, Dr. Griffith continued to be ahead of his time in urging, in turn, the by-pass system, small engines for jet lift, the use of hydrogen as a fuel, and had still other novel projects under consideration at the time of his death.

Dr. Griffith was born on June 13, 1893, and attended secondary school at Douglas in the Isle of Man. A Tate technical science scholarship took him to the University of Liverpool in 1911, where he obtained successively a B.Eng. (first-class honours in mechanical engineering), M.Eng. (1917) and D.Eng. (1921).

His first interest was in mechanies, and his joint paper with G. I. Taylor on the use of soap films in solving torsion problems gained the Hawksley Gold Medal from the Institution of Mechanical Engineers in 1917. His famous paper on "Theory of Rupture", in which he used surface energy considerations to dotermine the stress conditions under which a crack will propagate and lead to failure of a material, was published in 1920, and the concept of the 'Griffith Crack' was discussed at the first International Congress on Applied Mechanics at Delft in 1924.

He had no regular apprenticeship, but received general workshop training between July 1915 and November 1916 at the Royal Aircraft Factory. Following this training, he was successively draughtsman, technical assistant and senior technical assistant in the Physics and Instrument Department at the Royal Aircraft Establishment. During April 1920-April 1928 he was a senior scientific officer in the Physics and Instrument Department, Royal Aircraft Establishment, and then principal zcientific officer in charge of the Air Ministry Laboratory, South Kensington, until April 1931, dealing chiefly with engine and instrumont work.

During this period he became a firm advocate of the gas turbine for aircraft propulsion, and in 1926 wrote a Royal Aircraft Establishment report ontitled "An Aerodynamic Theory of Turbine Design", in which he formulated a number of new ideas. Under his supervision, work on a turbo-compressor test rig was started at the Establishment in 1927.

In 1931, Dr. Griffith was mado principal seientific officer in charge of engine research, Engine Department, Royal Aircraft Establishment; in November 1938, the 
acting head of the Department, and later head of the Department at the Royal Aircraft Establishment until May 1939.

During 1921-31, he was an official momber of the Elasticity and Fatigue Sub-Committee of the Aeronautical Research Council and then official member of the Engine Sub-Committeo, Aeronautical Research Council, until 1939. His connexion with the Council continued until his retirement in 1960. Indeed, in his later years he used the Committee as his main vehicle of communication with the technical world; he published little elsewhere, largely because of the relevance of his work to defence projects.

$\mathrm{He}$ was a founder member of the Gas Turbine Collaboration Committee.

On June 1, 1939, Dr. Griffith took up the position of research engineer of Rolls-Royce, Ltd., at Derby, working on the initiation and prosecution of aero engino research, responsible to Mr. E. W. Hives, general manager (later Lord Hives, chairman). He was given a pleasant room at Duffield Bank House, a quiet haven on the banks of the Derwent, five miles from Derby.

Griffith's first work, completed in 1941, was an axial flow jet engine including twenty contra-rotating compressor stages, each driven independently by turbine blades at the tips of the compressor blades, ducted fan propulsion, centrifugal fuel supply and other items that were far in advance of contemporary practice. The highpressure part of the system was, in fact, built and tested. Throughout his work on jet propulsion, Dr. Griffith believed in the superior efficiency of the axial type compressor, and the contra-flow engine was followed by a series of design investigations of axial types, parallel with work on many component rig test investigations of com. bustion, blade form and rotor design.

A technical memorandum prepared by Dr. Griffith in 1945 , togother with a preliminary design scheme created under his supervision, were the basis of the Rolls-Royce Avon engine; this was followed in 1946 by his proposals for a by-pass engine. Preliminary design schemes for the latter type were completed early in 1947 and led to the Rolls-Royce Conway engine.

Early in 1941, Dr. Griffith realized that the thrust potential of a turbine ongine, combined with its low weight, provided a basis for the design of an aircraft which could take off and land vertically by virtue of engine thrust alone and thus only need sufficient wing area for its cruise condition. He made a detailed investigation of engine weight relative to size and showed that the 'Square-Cube' law, by which an engine's weight decreases as the cube of its linear dimensions, whereas the thrust only decreases as the square, would hold good down to quite small unit sizes. This convinced him of the advisability of using a number of small engines in order to obtain the optimum lift/weight ratio for vertical take-off applications. His first design studies of vertical take-off aircraft incorporated a multiplicity of small engines with means for deflecting their thrust downwards for taking-off and landing; control of the aircraft in the jet-borne phase being by variation of the thrust of engines situated fore and aft for pitch and separated laterally for roll. The possibility, with this scheme, of difficulty due to insufficiently rapid thrustresponse rate led Dr. Griffith to the idea of using compressed-air jets fed from engine compressor air bleed.

He conceived the scheme for testing this system, now well known as the 'Flying Bedstead', and supervised the preliminary design scheme, which incorporated two RollsRoyce Nene turbine engines arranged back to back with their thrust deflected downwards in a central position. Control air was tapped from the engine compressors and fed to control nozzles positioned fore and aft and on outriggers laterally. On August 3, 1954, this jet-lift test rig achieved its first free flight for $8 \frac{1}{2} \mathrm{~min}$. Many subsequent flights clearly demonstrated the success of Dr. Griffith's vertical take-off proposals. Parallel with these tests and until his retirement in 1960, Dr. Griffith initiated many aircraft design studies using specially designed lightweight lift engines and separate engines for forward thrust. Late in 1953 he commenced a detailed investigation of a supersonic jet-lift transport designed for a Mach No. of $2 \cdot 6$ at $60,000-\mathrm{ft}$. altitude.

Dr. Griffith's work was recognized by fellowship of the Royal Society in 1941, a C.B.E. in 1948, the award of the Silver Medal of the Royal Aeronautical Society in 1955 and, in 1962, the Bleriot Medal.

Although Dr. Griffith was very little known to most people within Rolls-Royce, due partly to the secluded location of his office, I was privileged to be his personal assistant and designer for twenty-one years, sharing his office for sixteen years at Duffield Bank House and later having an adjoining design office at Littloover Old Hall for the five years prior to his retirement.

Alan Arnold Griffith was truly a man of vision, quiet and rotiring, resisting publicity yet fascinating to know intimately by daily contact. His brain provided new lines of thought for development in a continuous flow and our discussions were often enlivened by his ready wit and good humour.

Donald Eyre

\section{Prof. E. P. Sharpey-Schafer}

Edward Peter Sharpey-Schafer, professor of medicine in the University of London at St. Thomas's Hospital Medical School, died on October 23 at the age of fifty-five.

His father was killed in the First World War and consequently he was brought up in the house of his famous grandfather, Sir Edward Sharpey-Schafer. He went to school at Winchester and entered King's College, Cambridge, as an exhibitioner and Kitchener Scholar. His clinical studies were completed at University College Hospital, where he obtained the Fellowes Gold and Silver Medals. After qualifying, he held the post of house physician to Sir Thomas Lewis, a position which he spoke of with great pride in later years. After serving as resident medical officer at the National Heart Hospital, he joined Sir Francis Fraser as first assistant in the Department of Medicine in the early days of the Postgraduate Medical School. He was appointed professor of medicine at St. Thomas's Hospital Medical School in 1948.

It is impossible to assess the enormity of the loss which St. Thomas's Hospital has suffered in the death of Prof. Sharpey-Schafer. He is the third member of their consultant staff to die in recent months, and though they were all men of high intellect and profound wisdom, he was undoubtedly the greatest of the three. Only those who were close to him had the opportunity to know him. He was essentially a shy man, which led people to think his manner brusque and off-hand, but his great human qualities showed themselves when he considered that someone was being treated unjustly. The same consideration for others was manifest in his investigations on patients : if ever it became apparent that one was suffering discomfort he immediately abandoned the procedure.

Prof. Sharpey-Schafer was an outstanding research worker, who is known throughout the world for his work on the circulation. However, he entered the field of original work in endocrinology and made important contributions in investigations of the thyroid, acromegaly and ovarian function. Although he forsook this sphere during the War, he still taught the younger endocrinologist some fundamental facts years later.

With Prof. J. McMichael he introduced cardiac catheterization as a method of examination of the cardiovascular system. From then onwards he continued to be fascinated by the control mechanisms in this system in health and disease. Every woek he continued to make simple but fundamental observations on his patients, and a steady stream of original work flowed from his pen. He investigated hæmorrhage and heart-failure and remarked on the aspects of similarity in these two conditions. One of his 